\title{
Synchronic and diachronic evidence for parallels between noun phrases and sentences
}

\author{
Jan Rijkhoff
}

\begin{abstract}
It has been shown that, up to a point, noun phrases and clauses have the same underlying structure: they share the same kind of 'layered' organization and accommodate the same kind of semantic modifier categories (Rijkhoff 2008a). This article presents synchronic and diachronic evidence to substantiate the claim that there are parallels between the layered analysis of the noun phrase and the clause. It will be argued that the layered NP/clause model is supported by two largely unidirectional historical developments in language, one metaphorical in nature ('from space to time') the other metonymic ('from inner to outer layer').
\end{abstract}

\section{Introduction ${ }^{1}$}

Both formal and functional linguists have developed models in which clauses and noun phrases (henceforth NPs) can at least partly be analyzed in a similar fashion. But whereas purely formal approaches to grammar have concentrated on similarities between the (underlying) syntactic structure of the NP and the clause (e.g. Jackendoff 1977, Abney 1987), functional theories such as Functional Grammar or Functional Discourse Grammar have investigated parallels between the underlying semantic structure of the NP and clause (e.g. Rijkhoff 1988, 1992, 2002, 2008a-b). This article has two main goals: [a] to present a revised and expanded version of the layered (semantic) $\mathrm{NP} /$ clause model presented in Rijkhoff (2002), and [b] to give synchronic and diachronic evidence in favour of this particular model.

1. Abbreviations: $1=$ first person, $3=$ third person, $\mathrm{A}=$ adjective, $\mathrm{ABS}=$ absolutive, $\mathrm{ASP}=$ aspect, $\mathrm{C} 1$ = noun class $1, \mathrm{CLF}=$ classifier, $\mathrm{CN}=$ connector, $\mathrm{DEF}=$ definite, dem $=$ demonstrative, $\mathrm{DET}=$ determiner, $\mathrm{DS}=$ different subject, $\mathrm{ES}=$ ergative suffix, $\mathrm{ERG}=$ ergative, $\mathrm{EXH}=\mathrm{ex}-$ hortative, $\mathrm{F}=$ feminine, FUT = future tense, GENR = general aspect-tense-mood marker, IMP = imperative, $\mathrm{IMPF}=$ imperfective, $\mathrm{INDEF}=$ indefinite, $\mathrm{INF}=$ infinitive, INGR $=$ ingressive, $\mathrm{IRR}=$ irrealis, $\mathrm{LOC}=$ locative, $\mathrm{N}=$ noun, $\mathrm{NEG}=$ negative, $\mathrm{NP}=$ noun phrase, num = numeral, $\mathrm{PAST}=$ past tense, $\mathrm{PL}=$ plural, $\mathrm{POSS}=$ possessive, $\mathrm{PROH}=$ prohibitive, $\mathrm{PRT}=$ participle, Rel . $\mathrm{cl}=$ relative clause, $\mathrm{SG}=$ singular, $\mathrm{SIM}=$ simultaneous, $\mathrm{SS}=$ same subject, $\mathrm{SUPP}=$ support verb, $\mathrm{V}=$ verb. 


\section{Parallels between the semantic (layered) representation of the NP and the clause}

There are at least three functional approaches to grammar that make use of so-called layered structures in the representation of linguistic constructions: Halliday's Systemic Functional Grammar (Halliday 2004), Van Valin's Role and Reference Grammar (Van Valin and LaPolla 1997), and Dik's Functional Grammar (Dik 1997) as well as its successor Functional Discourse Grammar (Hengeveld and Mackenzie 2006, 2008). Here I will only be concerned with the layering in Functional Grammar and Functional Discourse Grammar, henceforth collectively referred to as F(D)G. ${ }^{2}$

Layering was introduced in 'standard' FG in 1989, when Dik adopted Hengeveld's (1988) ideas concerning the scoping of categories such as illocution (interrogative, declarative etc.), mood, tense, and aspect. Inspired by work in other functional approaches to grammar, Hengeveld (1989) proposed a new model of the clause, which consisted of hierarchically ordered layers, each accommodating its own set of grammatical and lexical modifiers, called operators and satellites (i.e. non-arguments or adjuncts) respectively in $\mathrm{F}[\mathrm{D}] \mathrm{G}$. His model only applied to clauses, but subsequently Rijkhoff $(1988,1990)$ also proposed a layered model of the NP, arguing that - up to a point - the underlying semantic structure of NPs and sentences is basically identical. The most recent version of this NP/clause model (Rijkhoff $2008 \mathrm{a}-\mathrm{b}$ ) is represented in Figure 1 below, in which operators and satellites are distributed over two levels in the FDG model: the Interpersonal Level and the Representational Level.

Grammatical modifier categories of the NP (e.g. definiteness, number) are symbolized by $\omega / \Omega$; grammatical modifier categories of the clause (e.g. mood, tense, aspect) are symbolized by $\pi / \Pi$. Lexical modifiers in the NP are represented by the symbol $\tau / \mathrm{T}$ (adjectives, relative clauses, etc.) and in the clause by $\sigma / \Sigma$ (adverbs, adverbials); subscripts 0 to 6 indicate the layer at which modifiers are specified.

The layers are organized hierarchically, which means that modifiers that are specified in the highest layer of the clause (illocutionary modifiers $\Pi_{6}, \Sigma_{6}$ ) have the widest scope (the whole message), whereas the scope of clausal modifiers represented at the lowest layer (classifying modifiers $\pi_{0}, \sigma_{0}$ ), which indicate what kind of event is being referred to, is restricted to the main predicate (typically a verb). By definition, members of a grammatical modifier category (i.e. operators) constitute a smallish, closed set of items, capturing only a limited number of crucial, absolute distinctions (Dik 1997: 160). For example, if Definiteness is a grammatical category in a language, the only two available choices are + Definite or - Definite (Indefinite). Qualifying operators $\left(\omega_{1}, \pi_{1}\right)$ are not deemed to exist (Rijkhoff 2008a). Since qualities are typically gradable rather than absolute properties, they can only be expressed through lexical modifiers: a house can be 'rather big ${ }_{\mathrm{A}}$ ' but not 'rather singular' or 'rather definite'.

2. See Butler (2003: 239-246) for a comparison of layering in Systemic Functional Grammar, Role and Reference Grammar and Functional (Discourse) Grammar. 


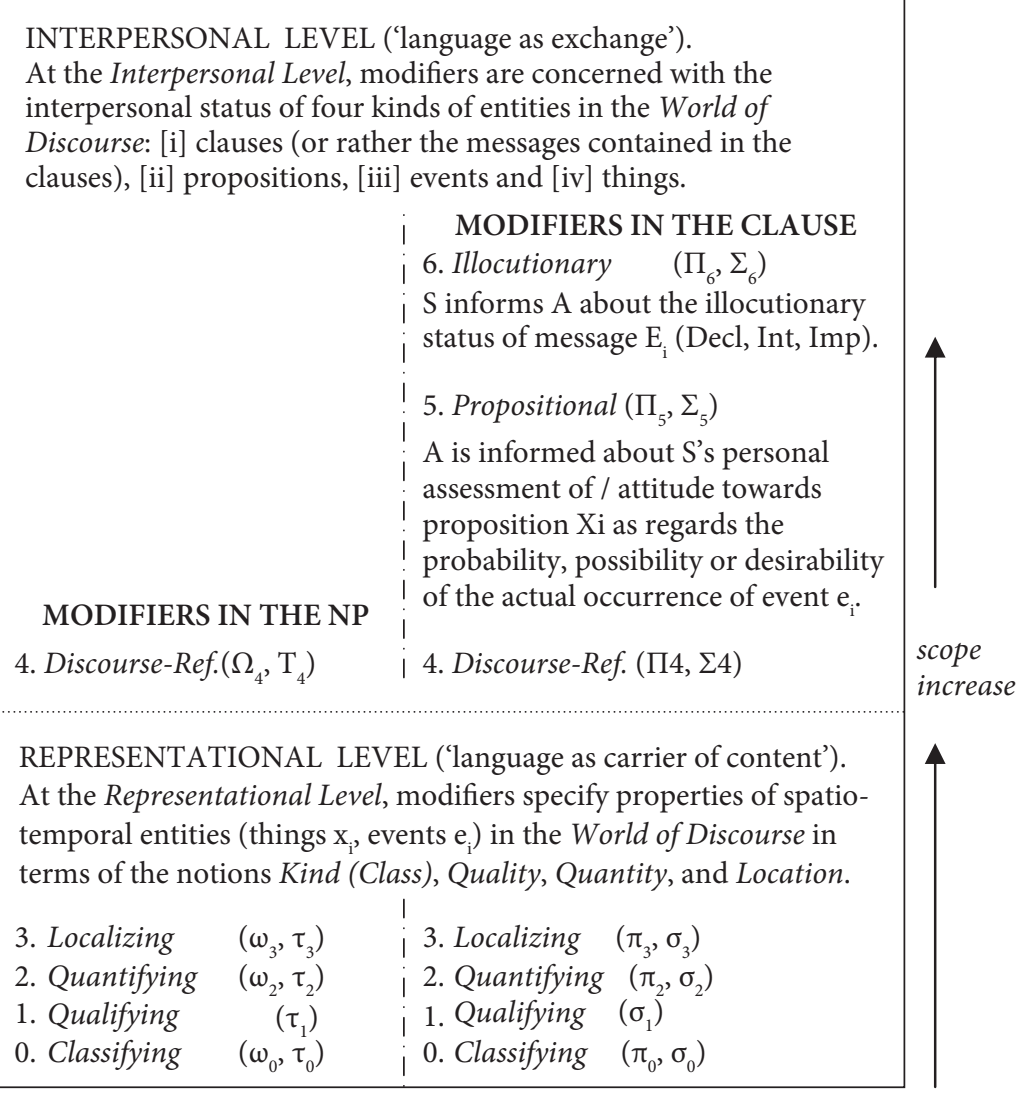

Figure 1. Layers of modification in the NP and in the clause

(Discourse-Ref. $=$ Discourse-Referential)

The classifying layer ('Kind') contains the head of the construction (noun, verb) and accommodates modifiers (classifying modifiers) that only relate to the property that is designated by the head, such as nominal or verbal aspect markers. The quality layer accommodates qualifying modifiers, which specify more or less inherent properties of the entity as designated by material in the kind layer, typically qualifying adjectives (if a language has them), and adverb(ial)s of manner, speed or duration. The quantity layer contains the quality layer and accommodates quantifying modifiers, which express number distinctions (SINGULAR, PLURAL) or specify the cardinality of the referent. In its turn the quantity layer is contained by the location layer, which accommodates localizing modifiers such as demonstratives, tense markers, or adverb(ial)s such as 'in the garden' or 'yesterday'. 


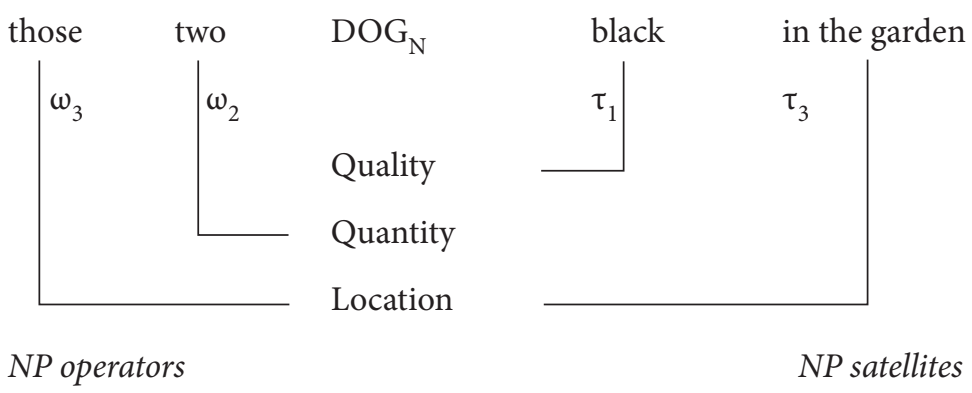

Figure 2. Simplified representation layers of modification in the NP'those two black dogs in the garden'.

In the NP 'those two black dogs in the garden' the qualifying modifier 'black' only relates to the noun 'dog', not the quantity or the location. The quantifying modifier 'two' specifies the number of black dog entities, not the number of locations; and both 'those' and 'in the garden' specify the location of the dog entities with all their qualitative and quantitative properties (Figure 2; notice that this example has no classifying or discourse-referential modifiers). ${ }^{3}$

It is important to emphasize there is no one-to-one correlation between the form and the function of a modifier; this holds in particular for lexical modifiers $(\sigma / \Sigma, \tau / T)$. For example, an adnominal prepositional phrase (PP) can occur as a localizing satellite $\left(\tau_{3}\right)$, a quantifying satellite $\left(\tau_{2}\right)$, or as a qualifying satellite $\left(\tau_{1}\right)$ in the NP (Rijkhoff forthcoming).

\subsection{Two levels: Interpersonal and representational}

Figure 1 shows that modifiers in the NP and in the clause can be divided into two major subcategories: interpersonal and representational (or descriptive) modifiers (Hengeveld and Mackenzie 2008). This division reflects the double function of NPs and clauses (Rijkhoff 2002: 231): they provide a physical description of a thing or an event and at the same time they are the constructions used to refer to entities in the world of discourse created by the interlocutors. The two levels are briefly discussed in turn below.

3. The reader is referred to Dik (1997) and Hengeveld and Mackenzie (2008) for an account of the way the layered underlying semantic structure is turned into an actual linguistic expression in FG and FDG respectively. 


\subsubsection{Modifiers at the Interpersonal Level}

The Interpersonal Level is regarded as that part of the grammar that is concerned with 'language as exchange' or 'language as communicational process' (Butler 2003: 111; Halliday 2004: 61) and has three layers of modification, accommodating

- discourse-referential modifiers for things or events (i.e. first and second order entities), which are specified at the fourth layer;

- proposition modifiers for propositions (i.e. third order entities), which are specified at the fifth layer;

- illocutionary modifiers for clauses (or rather: the message contained in the clause, a fourth order entity), which are specified at the sixth layer.

Grammatical and lexical modifiers (operators and satellites, resp.) at the Interpersonal Level in Figure 1 inform the Addressee about

a. the existential status of a spatial or temporal entity (thing $\mathrm{x}_{\mathrm{i}}$ and event $\mathrm{e}_{\mathrm{i}}$ ) in the world of discourse (more on this below);

b. the modal status of proposition $\mathrm{X}_{\mathrm{i}}$, in particular the speaker's mental or cognitive attitude towards the proposition; at this level we find, for example, grammatical and lexical expressions of subjective modality and evidentiality (Dik 1997: 295-299);

c. the illocutionary status of the clause; some relevant operator categories are Declarative, Interrogative, Imperative, Exclamative (on illocutionary satellites, see Dik 1997: 300-307).

Since this paper is concerned with parallels between NP and clauses, I will only be concerned with modifiers at the Interpersonal level that are specified at the fourth layer, the so-called 'discourse-referential modifiers' in Figure 1 (notice that I confine myself to NPs used to refer to concrete objects or 'things', so NPs such as 'last week's meeting', 'her true love' or 'your bad answer' will be ignored here; see also footnote 5).

Discourse-referential modifiers relate to the status of the referent (thing, event) in the world of discourse (Rijkhoff and Seibt 2005; Rijkhoff $2008 \mathrm{a}-\mathrm{b}$ ) in that they specify whether or not an entity occupies a certain spatio-temporal region in the discourse world. The relevant grammatical modifier categories are Definite/Indefinite and Specific/Non-specific in the NP and Realis/Irrealis in the clause. Adverbs and adjectives such as 'actually' and 'same' are instances of discourse-referential satellites.

The relation between discourse-referential operators is particularly interesting because it is symmetrical in one way and anti-symmetrical in another (with a special role for Specificity). ${ }^{4}$ The grammatical categories Realis and Definite are similar because they both indicate that the entity, i.e. the event or thing referred to by the speaker,

4. In order to explain symmetrical and anti-symmetrical relations between (ir)realis and (in) definiteness, we need to distinguish between specific and non-specific indefinite reference. Consider the following examples, which show that there are two ways to continue 'Max wants a dog' (Karttunen 1976). 
(already) has a certain location (is 'grounded') in the shared world of discourse. By contrast, Irrealis and (non-specific) Indefinite signal that the entity referred to by the speaker does not have a proper location (is not 'grounded') in the world of discourse at least not yet. There are thus two symmetries, one linking the grammatical categories Realis and Definite, the other linking Irrealis and Non-specific Indefinite (Figure 3).

\begin{tabular}{lll}
\hline NOUN PHRASE (thing) & $\begin{array}{l}\text { OCCURRENCE IN } \\
\text { WORLD OF DISCOURSE }\end{array}$ & CLAUSE (event) \\
\hline DEFINITE & $\begin{array}{l}\text { thing or event (already) has a location in REALIS } \\
\text { the discourse world, i.e. the entity is } \\
\text { 'grounded' }\end{array}$ \\
NON-SPECIFIC INDEFINITE & $\begin{array}{l}\text { thing or event does not have a location in IRREALIS } \\
\text { the discourse world (yet), i.e. the entity is } \\
\text { not 'grounded' }\end{array}$ \\
\hline
\end{tabular}

Figure 3. Symmetry between Definite/Realis and Non-specific Indefinite/Irrealis

The idea that irrealis and non-specific indefinite reference are closely related is supported by the fact that in some languages, such as Jacaltec (Mayan), the same marker is used to express these notions (variation is due to vowel harmony): ${ }^{5}$

Jacaltec (Craig 1977: 93):

(1) Way-oj ab naj sleep-OJ EXH CLF/he

'Would that he slept!' [-oj: exhortative mood]

(2) $X-\varnothing$-'oc heb ix say-a' hun-uj munlabel

ASP-ABS.3-start PL woman look_for-FUT a-OJ pot

'The women started looking for a pot.' [-oj marks non-specific reference]

Anti-symmetry between (in)definiteness and (ir)realis has to do with the number of ways that an entity can be definite/indefinite (thing) or actual/non-actual (event). Here
a. Specific-indefinite reference: Max wants a dog. It is black
b Nonspecific-indefinite reference: Max wants a dog. It must be black.

The difference is due to the fact that in a. reference is made to a specific dog ('Max wants a certain dog, which is known to be black'), whereas in b. the speaker does not refer to any particular dog (English has no special article for specific or non-specific reference unlike, for example, many Polynesian or sub-Saharan African languages).

5. For another example, see Du Feu $(1987,1989,1996)$ on Rapanui he, which used to mark both 'indefinite action' (-tense) and nonspecificity. Nordlinger and Sadler (2004) discuss aspect/ tense/mood marking on nominals. 
Definite aligns with Irrealis in that both definite things (referents of definite noun phrases) and non-actual events (referents of irrealis clauses) can occur in the world of discourse for many different reasons. Thus, the referent of an NP can be definite, for example, because

- $\quad$ it has been mentioned before (anaphoric use)

(3) I just bought a book and a calendar. Surprisingly, the book was much cheaper than the calendar.

- $\quad$ it is available in physical context (situational or deictic use)

(4) Now tell me - what do you see on the monitor?

Similarly, there are many reasons why an event is non-actual, as is shown in these examples from the Papuan language Amele (Roberts 1990: 371-372; see also Elliott 2000).

$\underline{\text { Amele }}$

(5) Ho bu-busal-eb age qo-qag-an pig SIM-run.out-3SG.DS.IRR 3PL hit-3PL-FUT

'They will kill the pig as it runs out.'

(6) Ho bu-busal-eb age qu-ig-a pig SIM-run.out-3SG.DS.IRR 3PL hit-3PL-IMP

Kill the pig as it runs out!'

(7) Ho bu-busal-eb cain qu-wain pig SIM-run.out-3SG.DS.IRR PROH hit-NEG.F.3PL

'Don't kill the pig as it runs out!'

By contrast, there is basically one reason why an NP is (specific) indefinite: because the entity (thing) designated by the indefinite NP has not been properly introduced in the world of discourse - hence the speaker assumes that the addressee does not know (yet) what particular thing is being referred to. There is also only one reason why a sentence is in the realis mood: because the entity (event) designated by the sentence is real, i.e. it has happened (or is happening). Thus anti-symmetry between (in)definiteness and (ir)realis is due to the fact that

a. referents of definite NPs and referents of irrealis clauses are part of the world of discourse for many different reasons;

b. referents of specific indefinite NPs and referents of realis clauses exist in the world of discourse for one and the same reason: they 'ground themselves' in the world of discourse when being referred to for the first time (Figure 4). 


\begin{tabular}{llll}
\hline $\begin{array}{l}\text { NOUN PHRASE } \\
\text { (thing) }\end{array}$ & \multicolumn{1}{c}{$\begin{array}{c}\text { NUMBER OF REASONS FOR AN ENTITY TO BE } \\
\text { MARKED AS (IN)DEFINITE OR (IR)REAL }\end{array}$} & $\begin{array}{c}\text { CLAUSE } \\
\text { (event) }\end{array}$ \\
\hline DEFINITE & many & $\begin{array}{l}\text { one } \\
\text { (grounds itself) }\end{array}$ & REALIS \\
SPECIFIC INDEFINITE & one (grounds itself) & many & IRREALIS \\
\hline
\end{tabular}

Figure 4. Anti-symmetry between Definite/Realis and Specific Indefinite/Irrealis

\subsubsection{Modifiers at the Representational Level}

The Representational Level deals with language 'as carrier of content' (Butler 2003: 111). Descriptive modifiers are concerned with properties of the referent of the NP (thing) or clause (event) in terms of the notions Class or Kind (what kind it is), Quality (how it is), Quantity (how much/many it is) and Location (where it is).

\subsubsection{Localizing modifiers}

Localizing modifiers specify locative properties of the entity (thing, event) as defined by material in the quantity layer. Grammatical expressions of the notion 'location' such as adnominal demonstratives are referred to as localizing operators; a lexical expression such as the adnominal NP 'on the wall' in 'the picture on the wall' is an example of a localizing satellite.

- localizing operators $\omega_{3}$ and $\pi_{3}$

Adnominal demonstratives $\left(\omega_{3}\right)$ are grammatical manifestations of the notion location in the NP. As is the case with other modifier categories, they do not occur in all languages (see e.g. Derbyshire (1979: 131) on Hixkaryana), and in some languages they require the presence of a classifier or a definite article.

Mandarin Chinese (Li and Thompson 1989: 105)

\section{(8) nèi-tiáo niú \\ DEM-CLF COW \\ 'that cow'}

Since tense is "[..] grammaticalised expression of location in time" (Comrie 1985: 9), inflectional tense markers $\left(\pi_{3}\right)$ are obviously instances of localizing operators at the level of the clause.

- localizing satellites $\tau_{3}$ and $\sigma_{3}$

Recall that there is no one-to-one relationship between the form of a modifier and its place in the layered representation of a linguistic construction. Thus, a localizing satellite in the NP can take the form of an adnominal prepositional phrase such as 'on this carpet', as in: 
(9) The stain on this carpet was difficult to remove.

Restrictive relative clauses and possessive modifiers ('genitives') are also typically used as localizing satellites (Rijkhoff 2002: 173-178, 194-211; on the relationship between possession and location, see e.g. Clark 1978 and Heine 1997).

(10) Could you give me the book that is lying on that table Rel.cl $_{\text {? }}$ ?

(11) I'd like to talk to the father of that boy ${ }_{\text {Poss.NP. }}$.

It is essential for the localizing satellite to provide a referential anchor for the addressee, i.e. the localizing satellite must contain a reference to an entity that is easily identifiable for the addressee and which makes it possible to locate the referent of the matrix NP. In the examples above the referential anchors are: 'this carpet', 'that table' and 'that boy'. They enable the hearer to locate (and identify) the referents of the embedding matrix NPs: 'the stain', 'the book', and 'the father' respectively. Referential anchors also play an important role in presupposition (Rijkhoff 2002: 176, Rijkhoff forthcoming).

\subsubsection{Quantifying modifiers}

Quantifying modifiers specify quantitative properties of the referent (thing or event) and relate to all the material contained in the quality layer. Grammatical expressions of the notion 'quantity' are quantifying operators; lexical expressions are called quantifying satellites (Rijkhoff 2002: chapter 5).

- quantifying operators $\omega_{2}$ and $\pi_{2}$

In many languages number distinctions are either optional or altogether absent in the NP (Rijkhoff 2002: 106-119, 146-155), but if nominal number is a relevant category in some language it is commonly expressed by some grammatical element like a nominal affix:

Dutch

(12) fiets-en

bicycle-PL

'bicycles'

In the absence of clear lexical properties, adnominal cardinal numerals are often categorized as 'form words' rather than 'content words' in many languages (notice that the atoms of a numeral system constitute a closed class; Greenberg 1978b: 256):

Hungarian (Moravcsik 1994: 8)

(13) két lány

two girl

'two girls'

Some languages also employ grammatical means to indicate how often an event takes place. When reference is made to a single occurrence this is called semelfactive aspect 
and in the case of multiple occurrences this is called iterative, repetitive, or frequentative aspect. This example from Hidatsa (Amerind) contains such a number marker at the level of the clause (glossed as 'iterative mood' in the source grammar):

Hidatsa (Matthews 1965: 158)

(14) Wí i hírawe ksa c woman she sleep INGR ITER.MOOD

'The woman kept falling asleep.'

- quantifying satellites $\tau_{2}$ and $\sigma_{2}$

In quite a few languages across the globe cardinal numerals are categorized as lexical elements or they appear as predicates (Rijkhoff 2002: 168-172). For example, in Krongo numerals are categorized as verbs, which appear in the imperfective when they modify a noun $\left(\tau_{2}\right)$ :

Krongo (Reh 1985: 252)

\section{nóo-còorì nk-óotòonò \\ PL-house CN.PL-IMPF:be_three}

'three houses'

In Samoan the numeral appears as the head of a special kind of relative clause introduced by the general tense-aspect-mood marker [GENR] $e$ if the NP has specific reference.

Samoan (Mosel and Hovdhaugen 1992: 318)

$$
\begin{aligned}
& \text { Sa fau=sia e Tagaloaalagi fale e tolu ... } \\
& \text { PAST build=ES ERG Tagaloaalagi house GENR three ... } \\
& \text { 'Tagaloaalagi built three houses... }
\end{aligned}
$$

Adverbs and adverbials are typically employed as lexical modifiers to specify how often an event occurs $\left(\sigma_{2}\right)$, as in:

(17) Every once in a while/Sometimes/Rarely our cat catches a mouse.

\subsubsection{Qualifying modifiers}

Qualifying modifiers specify more or less inherent properties (qualities) of the referent. Lexical expressions of the notion Quality are referred to as qualifying satellites; recall that there are no qualifying operators (section 2).

- qualifying satellites $\tau_{1}$ and $\sigma_{1}$

Qualifying satellites are lexical modifiers specifying notions such as size, weight, color, age, and value in the case of things and manner, speed or duration in the case of events. They are typically expressed by adjectives (in the NP) or adverbs (in the clause) - if a language has these lexical categories. 
(18) a beautiful Adj $_{\text {song }}$

(19) She sang beautifully $_{A d v}$

Adjectives and adverbs are, however, not attested in every language. If a language lacks a distinct class of adjectives, it will usually employ qualifying NPs or relative clauses instead, as in the English paraphrases 'the man with richness' or 'the man who is rich'. Speakers of Galela, for example, use a kind of relative clause (headed by a stative verb) and Hausa speakers employ an adnominal NP (headed by an abstract noun). Notice that the first syllable of the attributive verbal predicate in question is reduplicated in Galela, yielding the participial form.

Galela (van Baarda 1908: 35)

(20) awi dohu i lalamo

his foot it be_big:PRT

'his big foot'

Hausa (Schachter 1985: 15)

(21) mutum mai alheri / arzaki / hankali

person with kindness / prosperity / intelligence

'a kind/prosperous/intelligent person'

Wambon is one of the languages that, apart from one or two exceptions, has no distinct class of adverbs. This language employs medial verb constructions to express qualitative notions at the level of the clause (the verb matetmo is derived from the adjective matet 'good').

Wambon (de Vries 1989: 49)
Jakhov-e matet-mo ka-lembo?
they-CN good-SUPP.SS go-3PL.PAST
'Did they travel well?'

\subsubsection{Classifying modifiers}

Classifying modifiers further specify the kind of entity denoted by the noun or verb and appear at the innermost layer of modification, i.e. between the head constituent and the layer that accommodates qualifying modifiers.

- classifying operators $\omega_{0}$ and $\pi_{0}$

Classifying operators are grammatical modifiers that (further) specify what kind of spatial or temporal entity is being referred to. Just as verbs are coded for a particular Aktionsart ('mode of action': activity, achievement, state etc.), nouns are lexically coded for a particular Seinsart ('mode of being': singular object, mass, set, collective etc.; Rijkhoff 1992, 2002). And just as verbal aspects like 'perfective' and 'imperfective' modify the Aktionsart (or lexicalized aspectuality; Dik 1997: 224f.), nominal aspect 
markers can change the Seinsart of a noun (Rijkhoff 2002: 100-121). For example, nouns in Oromo are lexically coded for a Seinsart that I have called 'set' (meaning that Oromo nouns are transnumeral and can be in a direct construction with a numeral), but when they are provided with a (what I call) collective or an individual aspect marker, they designate a special kind of set, viz. a collective set or a singleton set (with just one member) respectively:

Oromo (Stroomer 1987: 76-77, 84-85)

(23) farda 'horse/horses' (unmarked set) vs. fardoollee 'horses' (collective set)

(24) nama 'man/men' (unmarked set) vs. namica 'a/the man' (singleton set)

- classifying satellites $\tau_{0}$ and $\sigma_{0}$

Classifying satellites in the NP are lexical items that further specify what kind of entity is being denoted by the head noun, for example: annual in 'annual report', presidential in 'presidential election', electric in 'electric train', social in 'social security', of sin in 'house of sin' (Rijkhoff forthcoming). They typically appear adjacent to the head noun and differ from qualifying satellites in that they do not specify an objective property of the entity (round table, red car) or the speaker's subjective attitude towards the entity (interesting dissertation, beautiful picture), but rather a particular subclass of the entity in question. In English classifying adjectives differ from qualifying adjectives in that they usually do not admit intensifiers, comparison, or predicative position (Quirk et al. 1985: 1339; on non-predicative adjectives, cf. also e.g. Farsi 1968, Levi 1973; see also Giegerich 2005 on associative adjectives):

(25) an electric train

vs. ${ }^{*}$ a very electric train

[intensifier]

(26) a medical examination vs. * a more medical examination [comparison]

(27) the presidential election vs. ${ }^{*}$ the election is presidential [predicative position]

At the level of the clause, so-called 'stripped nouns' are good examples of classifying satellites (Miner 1986, 1989; Gerds 1998). Stripped nouns are rather similar to incorporated nouns, but the crucial difference is that a stripped noun is a separate word (according to phonological criteria such as stress placement), which must appear next to the verb. Thus, in Kusaiean adverbs can appear between verb and object (28a) but not between verb and stripped noun (28b).

Kusaiean (Gerds 1998: 94; original example in K. Lee 1975)

(28) a. Sah el twem upac mitmit sac

Sah he sharpen diligently knife the

'Sah is sharpening the knife diligently.' 
With stripped noun mitmit 'knife':

b. Sah el twetwe mitmit upac

Sah he sharpen knife diligently

'Sah is diligently knife-sharpening.'

In these examples a distinction is made between sharpening in general (28a) and a certain kind of sharpening, namely knife-sharpening (28b).

\section{Synchronic and diachronic evidence for parallels between the layered structure of NPs and clauses}

Some synchronic and diachronic evidence for the layered analysis of clausal structures was presented in Hengeveld (1989) and several subsequent publications. ${ }^{6}$ This section is specifically concerned with evidence in support of parallels between the layered organization of NPs and clauses, the most recent version of which is shown in Figure 1.

\subsection{Synchronic evidence}

\subsubsection{Morpho-syntactic parallels}

When we consider the relative order of demonstrative (dem), numeral (num), qualifying adjective $(\mathrm{A})$ and noun $(\mathrm{N})$ in languages across the globe, we find that ordering patterns typically reflect the layered (semantic) organization of the noun phrase presented above (Rijkhoff 2004). ${ }^{7}$

(29) dem num A N Alamblak, Dutch, Georgian, Hungarian, Kayardild, Ket, Nama Hottentot, Imbabura Quechua, Pipil, Tamil, Turkish

dem num N A Burushaski, Guaraní (also e.g. French and other Romance languages)

6. For evidence in favour of the layered model of the clause, see Dik et al. (1990) and other articles in Nuyts et al. (eds.) 1990; see also e.g. Dik and Hengeveld (199), Cuvalay-Haak (1997), Crevels (1999). For an early discussion of variables and scoping in FG, see Vet (1986).

7. Notice that we are only concerned with integral, non-complex NPs that are used to refer to concrete objects (see also section 2.1.1). This excludes, for example

- complex NPs, containing embedded modifiers such as relative clauses (recall that in many languages adjectival or numerical notions are expressed in the form of an embedded modifier);

- NPs containing bound modifiers (sometimes modifiers are expressed as clitics, affixes, incorporated forms or part of a compound);

- appositional forms of modification (in certain languages some or all modifiers may or must be in an appositional relation with the structure containing the head noun; Rijkhoff 2002: 19-23). 


$\begin{array}{ll}\text { dem A N num } & \text { Zande } \\ \text { dem N A num } & \text { Bambara } \\ \text { num A N dem } & \text { Berbice Dutch Creole, Bislama, Sranan } \\ \text { num N A dem } & \text { Basque, Hmong Njua } \\ \text { A N num dem } & \text { Sango } \\ \text { N A num dem } & \text { Oromo, Fa d'Ambu, Nubi }\end{array}$

In all patterns the localizing modifier (dem) is in the periphery and the qualifying adjective (A) immediately precedes of follows the noun, as in the following abstract schema:

(30) dem num A N A num dem

From a logical point of view there are 16 additional ordering possibilities ( $\mathrm{N}$ dem $\mathrm{A}$ num, num A dem N, etc.), but very few of these patterns have been attested so far. Languages that are deemed to use such 'non-iconic' NP internal ordering patterns are discussed in Rijkhoff (2002: 19-23, 273-276, 324-332; 2004), where it is argued that in none of these cases we are actually dealing with simple, integral NPs in which modifiers are expressed as free forms. For example, if adjectives do not appear next to the noun in some language, this is probably because they are actually verbs or nouns heading an embedded phrasal modifier (relative clause or noun phrase; cf. Heine 1980: 182, Dryer 1992: 96). It may be hypothesized that at least one of the following statements is true for the handful of languages that are assumed to display a 'non-iconic' word order pattern in the NP with respect to the ordering of demonstrative, numeral, adjective and noun.

- so-called adjectives are better categorized as verbs or nouns, i.e. adnominal relative clauses or NPs, turning the NP into a non-simplex construction (examples (20) and (21)); ${ }^{8}$

- numerals are expressed as phrasal modifiers, also turning the NP into a syntactically complex construction (examples (15) and (16));

- modifiers are expressed as bound rather than free elements, which means their expression is a matter of morphology rather than syntax;

- modifiers are in apposition (rather than fully integrated constituents). For example, in the Australian language Kalkatungu "there are in fact no noun phrases, but [..] where an argument is represented by more than one word we have nominals in parallel or in apposition. [...] Each word is a constituent of the clause [...]" (Blake 1983: 145; see also Blake 2001);

- modifiers are assigned a special pragmatic function like Focus, indicating we are dealing with a marked pattern (Rijkhoff 2002: 272-273).

A similar tendency to iconically adhere to the layered organization (albeit less strictly) is attested in ordering patterns at the level of the clause. In English, for example, differ-

8. Apart from languages without modifying adjectives, there are also languages without adnominal demonstratives or numerals as well as languages in which a certain adnominal modifiers never seem to co-occur in the same NP (Rijkhoff 2002: 329f.; Derbyshire 1979: 132; Everett 2005). 
ent kinds of temporal satellites tend to occur in the order time duration ('for a short while' = qualifying satellite), time frequency ('every day or so' = quantifying satellite) and time position ('in January' = localizing satellite), as in this example (Quirk et al. 1985: 551):

$$
\begin{array}{llll}
\text { I was there } & \text { for a short while } & \text { every day or so } & \text { in January } \\
& \text { Quality (duration) } & \text { Quantity (frequency) } & \text { Location (in time) }
\end{array}
$$

In her study on morphology, Bybee (1985: 196) investigated the ordering of inflectional morphemes relative to the verb in a sample of fifty languages. She found that aspect $\left(\pi_{0}\right)$ occurs closest to the stem, followed by tense $\left(\pi_{3}\right)$, and then by mood $\left(\Pi_{4} /\right.$ $\Pi_{5}$ ). The only exception to this ordering she found in her 50-language sample is in Ojibwa, where the dubitative suffix precedes the preterite suffix.

\subsubsection{Isomorphism I: NPs and clauses sharing the same lexical modifier}

Languages across the globe employ various kinds of parts-of-speech systems (Rijkhoff 2007). Figure 5 shows that there are both qualitative and quantitative differences between the parts-of-speech systems. Languages not only differ in the number of major word classes they employ, but also with respect to the degree of flexibility displayed by the members of a certain word class. For example, Samoan is deemed to have a single, extremely flexible class of contentives (Mosel and Hovdhaugen 1992: 73-74, 77), whereas Hungarian has four distinct lexical word classes: verbs, noun, adjectives and adverbs. For a detailed discussion of parts-of-speech systems, including the intermediate types (not indicated in Figure 5), the reader is referred to Hengeveld et al. (2004) and Hengeveld and Rijkhoff (2005).

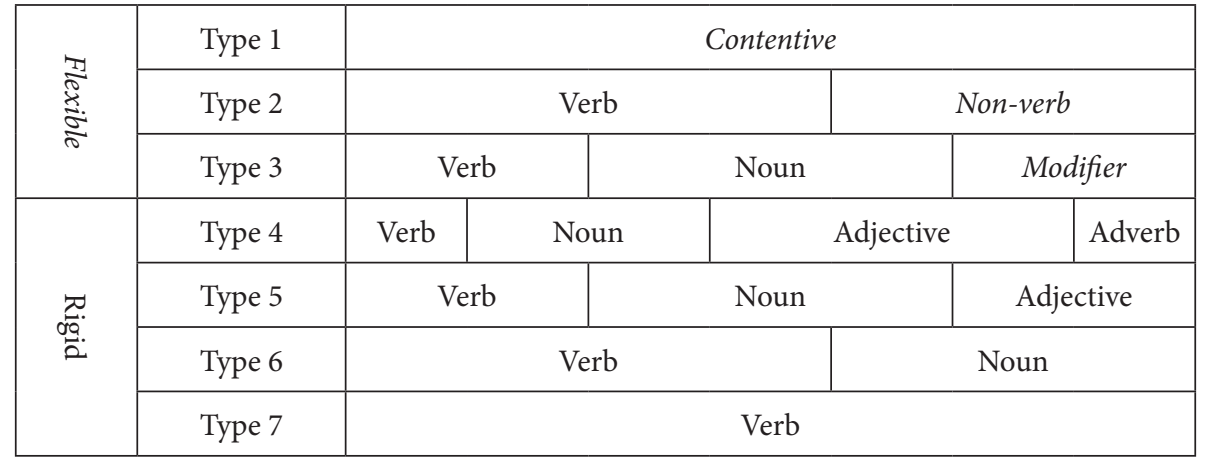

Figure 5. Parts-of-speech systems

(based on Hengeveld 1992; adverb = manner adverb).

In the present context, languages of Type 3 are of special interest, as in these languages nouns and verbs are modified by members of the same word class (called Modifier in 
Figure 5). Let us first consider an example from English, where manner adverbs are often derived from adjectives by adding the derivational suffix $-l y$.

(32) She recorded a beautiful song $_{N}$

(33) She sang beautiful $-l y_{\text {Adverb }}$

By contrast, languages of Type 3 such as Ngiti have a single word class (Modifier) whose members are all flexible in that they can all be used to modify nouns as well as verbs (Kutsch Lojenga 1994: 336):

[In Ngiti] there is no morphological nor a clear syntactic distinction between a class of adjectives and a class of adverbs in Ngiti. The functional term modifiers is therefore used [...] to cover a fairly large grammatical class of words, containing about 150 items, which are neither nouns nor verbs and which all have a modifying function in relation to different constituents.

In other words, in Ngiti and other languages of Type 3 we find that the same element is used as a quality satellite $\left(\sigma_{1}, \tau_{1}\right)$ in the NP and in the clause. The same true for Dutch:

Dutch

(34) Ze zong een mooi $_{\tau 1}$ lied she sang a beautiful song 'She sang a beautiful song.'

(35) Ze zong mooi she sang beautiful(ly)

'She sang beautifully'.

\subsubsection{Isomorphism II: NPs and clauses sharing the same grammatical modifier}

In quite a few languages, we also find the same grammatical modifier being used in the clause and in the NP. For example, several studies have remarked on phonological similarities between markers of nominal and verbal plurality, both quantifying operators (Frajzyngier 1977, 1997; Mithun 1988; Newman 1990; Gil 1993). More will be said about this in section on 3.2 on diachronic evidence for layering.

It was already mentioned in section 2.1.1 that in Jacaltec discourse-referential operators in the clause (Irrealis) and in the NP (Non-specific Indefinite) are formally identical. Fongbe (a Kwa language mainly spoken in Benin) is an example of a language that employs the same marker for realis and definite reference (glossed as DET, as in the original publication): ${ }^{9}$

9. The same goes for Haitian Creole (Fongbe is one of the substratum languages of Haitian Creole). 
Fongbe (Lefebvre 1998: 94, 99; see also Lefebvre and Brousseau 2002)

(36) $N$ dú àsón jo

I eat crab DET

'I ate the crab (in question/that we know of).'

(37) Jan wá j́

John arrive DET

'Actually, John arrived.'

Next we will consider some historical evidence in support of the hypothesis that each layer in the underlying structure of the NP has its counterpart in the underlying structure of the clause.

\subsection{Diachronic evidence}

According to the model in Figure 1, NPs and clauses can be analyzed in a similar fashion in that they share the same kind of layered organization and accommodate the same kind of modifier categories. For some categories there is evidence that clearly points to some diachronic connection between linguistic forms or constructions that are used to talk about spatial entities and those that are used for temporal entities (cf. also the examples from Jacaltec and Fongbe above). ${ }^{10}$

This section consists of three parts. Section 3.2.2 discusses historical connections between linguistic material relating to spatial and temporal entities (i.e. across linguistic constructions), section 3.2.3 is concerned with diachronic relations between modifier categories in the NP and in the clause (i.e. within linguistic constructions). First, however, historical relationships within and across the spatial and the temporal domain are considered from the perspective of grammaticalization (section 3.2.1), a special form of language change which crucially involves metaphor (a cognitive process based on analogy by transfer of features) and metonymy (a form of reanalysis based on associative relations). It will be argued that historical connections between linguistic material across the space-time boundary ('from space to time'), discussed in section 3.2.2, are largely due to metaphorical processes, whereas historical relations between grammatical modifiers inside the NP or the clause ('from inner to outer layer'), the topic of section 3.2.3, are metonymic in nature.

\subsubsection{Grammaticalization, metaphor, and metonymy}

Grammaticalization is defined as "the change whereby lexical items and constructions come in certain linguistic contexts to serve grammatical functions and, once grammaticalized, continue to develop new grammatical functions" (Hopper and Traugott 2003: xv). To give an example, the French preposition chez 'with, at' is historically

10. Note that this is not the same as saying that there is a diachronic relationship between NPs and clauses (see also below). 
derived from the (Latin) noun casa 'house'. The two most significant mechanisms that lead to grammaticalization are reanalysis and analogy (Hopper and Traugott 2003: chapter 3). Reanalysis is a covert, syntagmatic phenomenon and involves the morphological, syntactic, and semantic modification of forms and constructions: "the hearer understands a form to have a structure and a meaning that are different from those of the speaker" (Hopper and Traugott 2003: 50). For example, at some point in the history of French certain nouns were added to reinforce the negative element ne 'not' (as in 'I did not walk/take a[nother] step', 'I did not speak a[nother] word') but eventually these nouns were reanalyzed as being part of a larger negative construction. Subsequently one form (pas, an erstwhile noun meaning 'step') ousted all other variants and came to be used with verbs that had nothing to do with moving on foot (cf. Je ne sais pas 'I don't know'), regularizing part of the grammar. This last phase, where pas appears with any kind of verb, exemplifies the second mechanism: analogy. Analogy is an overt, paradigmatic phenomenon and refers to "the attraction of extant forms to already existing constructions" (ibid. 64).

Reanalysis and analogy are closely associated with two cognitive strategies: metonymy and metaphor respectively (Heine et al. 1991). Metaphor is discontinuous and involves a transfer of features from one conceptual domain to another, more abstract conceptual domain (Heine 2003: 586; see section 3.2.2). This is shown in the following hierarchy of conceptual domains (Heine et al. 1991: 48)

$$
\text { Person }>\text { Object }>\text { Activity }>\text { Space }>\text { Time }>\text { Quality }
$$

This conceptual shift toward more abstract categories is illustrated by the following examples from Ewe (Heine et al. 1991: 66 - my numbering):

In sentence (39), for example, megbé may denote both a body part ('back') and the 'back part' of an inanimate item, and in (40) it may mean either the 'back part' of an object or the 'space behind' that object. Sentence (41) again may have either a spatial or a temporal meaning. Finally, sentence (42) has both a temporal and a qualitative significance:

Ewe (Heine et al. 1991: 66)

$$
\text { megbé keke-ádé le é-sí }
$$

back broad-INDEF be 3SG.POSS-hand

a. 'He has a broad back.'

b. 'Its back is broad.'

(40) dzra xo-á pé megbé dó prepare house-DEF of back ready

a. 'Prepare the back wall of the house!'

b. 'Prepare the place behind the house!' 
(41) é-le megbé ná-m

3SG-be behind to-1SG

a. 'He is behind me.' (spatially)

b. 'He is late.' (= he could not keep pace with me)

(42) é-tsí megbé

3SG-stay behind

a. 'He remained behind/is late.'

b. 'He is backward/dull.'

Thus, one could regard the change from 'collective' to 'perfective' (see section 3.2.2.1 below), or the change from demonstrative pronoun to tense marker (i.e. from spatial to temporal deixis; see section 3.2.2.3), as instances of the metaphorical change from space to time. Notice, however, that we only have good evidence of markers of temporal notions having developed from markers for spatial notions, which is not the same as saying that grammatical modifiers at the level of the clause have developed out of grammatical modifiers in the NP. This is most clearly seen in the case of the localizing operators discussed in section 3.2.2.3, where it is mentioned that tense markers in Panare did not developed from adnominal demonstratives, but rather from free demonstrative pronouns.

Section 3.2.3 is more directly concerned with the other cognitive phenomenon that plays an important role in grammaticalization: metonymy. Metonymy is the result of a continuous process in which a certain context invites a specific (typically more abstract) interpretation of some linguistic form or construction. For example, in older forms of English the equivalent of the subordinating conjunction 'since' used to have a purely temporal meaning ('from the time that'), but it gradually acquired another, causal sense ('because'), as in certain contexts one could interpret the event described in the matrix clause as a consequence of the event described in the subordinate clause introduced by 'since' (Hopper and Traugott 2003: 82-83), as in:

(43) Since his wife left him, he buys his lunch at MacDonald's.

In this example 'since' can be interpreted as just a temporal subordinator, but it is not difficult to see a causal connection between the two events referred to in (43). ${ }^{11}$ This kind of process is also responsible for the fact that historically a grammatical modifier represented at some lower, more central layer in NP/clause model in Figure 1 tends to develop into a modifier at a higher, more peripheral layer (i.e. with a wider scope). ${ }^{12}$

11. Furthermore, there is nothing in the context that tells the addressee that the causal sense is not what the speaker had in mind when the sentence is uttered. This kind of reasoning is called 'abduction', an important component of language change (Hopper and Traugott 2003: 43).

12. Thus, the cases discussed here would all be instances of scope increase; cf. Song (2005) for a recent discussion on scope increase and scope decrease in grammaticalization. 
Thus the layered model seems to be supported by two kinds of historical developments. The historical relationships across the NP-clause boundary described in section 3.2.2 are mainly metaphorical in nature, in that elements to talk about entities that belong to one dimension (space) end up being used to also talk about entities of another dimension (time). The metonymic dimension of grammaticalization is best exemplified by the more or less continuous change 'from center to periphery' in the layered representation of linguistic structures (section 3.2.3). Changes along the two dimensions seem to be largely unidirectional (from space to time, from inner to outer layer). Some attention is also given to counterexamples to unidirectionality.

\subsubsection{Historical relations between modifiers across linguistic constructions}

\subsubsection{Qualifying modifiers}

Nearly a century ago Von Garnier (1909) already investigated historical connections between markers of collectivity and perfectivity (section 2.1.2.4). ${ }^{13}$ According to Leonid Kulikov (to whom this reference is due), the development from collective to perfective is attested in many Indo-European languages. ${ }^{14}$ Van Garnier's article contains evidence from e.g. Classical Greek, Latin, and Sanskrit. Kulikov states that languages from the Slavic branch of Indo-European (Old Church Slavic, Russian) went through the same historical process. We also find traces of this development in the modern Germanic languages. For example, the Germanic prefix ge- still has a collectivizing meaning in modern Dutch nouns like gebroeders '(collection of) brothers' and gebergte '(collection of) mountains' (in modern German Gebrüder and Gebirge, respectively). At some point in the history of Germanic this prefix came to be used with certain imperfective verbs to express the notion of completeness (i.e. perfectivity) and ultimately it became associated with the past participle form of the verb (Kirk 1923: 65), as in:

Dutch

(44) Hij heeft net een lied voor ons ge-zongen

he has just a song for us sung (past participle of 'sing')

'He just sang a song for us'

\subsubsection{Quantifying modifiers}

It was already mentioned in section 3.1.3 that in many languages there is a strong resemblance between markers of plurality in the NP and in the clause, i.e. between quantifying modifiers. Whereas in the case of qualifying operators (section 3.2.2.1) there seems to be general agreement on the direction of change (from collective to perfective,

13. The notions 'collective' and 'perfective' are both characterized by the feature of boundedness (Rijkhoff 2002: 53-59).

14. See Kulikov's message to the Discussion List for The Association for Linguistic Typology, 31 March 1998 (Subject: collective/perfective). The message can be found at: http://listserv.linguistlist.org/cgi-bin/wa?A2=ind9803e \&L=lingtyp $\& \mathrm{D}=1 \& \mathrm{~F}=\& \mathrm{~S}=\& \mathrm{P}=606$ 
i.e. from space to time), in the case of quantifying operators such as plural markers there is no consensus whether the change was from the spatial to the temporal domain, or rather the other way around. According to Newman (1990: 118), verbal plural markers in Chadic developed from the nominal plural markers. His proposal finds initial support by a large body of cognitive studies, which all seem to point to the importance of the "time-as-space" metaphor in human cognition (see also e.g. Haspelmath 1997). ${ }^{15}$ In fact, Lakoff (1993: 218) has argued that our metaphorical understanding of time in terms of space is biologically determined. Nevertheless Frajzyngier (1977) claims that verbal plural markers developed into nominal plural markers in the Chadic languages, and Mithun (1988) postulates the same development for a number of North American languages. There is, of course, also the possibility that number distinctions have their origin outside the spatial or temporal domain (Lehmann 1982). Frajzyngier (1997) argues that both nominal and verbal plural markers developed from the same source: a set of deictics, determiners and anaphors.

In the case of quantifying modifiers, there is perhaps another reason why it is difficult to decide on a preferred direction of change. If it is true that some numerical concepts are processed outside the language-based counting system, this may be reflected in the synchronic and diachronic behaviour of numerical expressions. ${ }^{16} \mathrm{I}$ am not aware of cognitive research on the processing of number distinctions in the clause $\left(\pi_{2}\right)$ and in the NP $\left(\omega_{2}\right)$, but a recent study investigating the relationship between language and arithmetic in speakers of Mundurukú, an Amazonian language with very few number words, suggests that there is "a distinction between a nonverbal system of number approximation and a language-based counting system for exact number and arithmetic" (Pica et al. 2004: 499).

\subsubsection{Localizing modifiers}

In their article on deixis, Anderson and Keenan (1985: 297) noted that in most languages "the spatial expressions are imported directly into the temporal domain by means of metaphorical representation of time as a spatial dimension [..]" as in "this week' or 'that evening'. Some languages have gone further in that erstwhile demonstratives ultimately developed into tense markers. In Panare (a Cariban language), for

15. Gil (1993: 281) claims that there is asymmetry between nominal and verbal quantification: “.., while nominal quantifiers can show up on the verb, ..., verbal quantifiers can never show up on a noun."

16. Also, intuitively the cognitive distance between operators in the clause and in the NP seems to be shorter for QUANTIFYING OPERATORS (both things and events can be Singular or Plural) than for e.g. QUALIFYING OPERATORS: although both things and events can occur 'collectively', the notion of 'completeness' or 'perfectivity' seems to belong much more to the temporal domain of events (see also below on the role of spatiotemporal ambiguity of certain deictic elements in grammaticalization processes). 
example, two tense-marking auxiliaries are derived etymologically from demonstrative pronouns (Gildea 1993: 53):

The original pronouns differed in spatial deixis, one marking proximate ('this'), the other distal ('that'). They came to be required between predicate noun and subject in predicate nominal clauses, and thus evolved into copulas. As copulas, the deixis of the pronouns shifted to time, with proximate becoming present or immediate future and distal becoming past (but also sometimes interpretable as distant future). These copulas then evolved further to become tense auxiliaries for a new generation of main clause verbs.

\subsubsection{Diachronic relations between modifiers in the NP and between modifiers in the clause}

Both in the clause and in the NP we find that a grammatical modifier at some inner layer may turn into an operator at some outer layer, again adhering to the layered organization outlined in Figure 1. More specifically, what we see is a tendency for operators in the clause and in the NP to widen their semantic scope as they move toward a more peripheral layer (scope increase). There are also cases of operators that seem to move toward the head of the NP or clause (scope decrease), but as far as I am aware this involves hybrid categories such as the perfect, which combines tense and aspect features and consequently may develop in either direction (see also note 4). We will first present some examples of the grammaticalization of clausal operators and then turn to the grammaticalization of operators in the NP.

\subsubsection{Grammaticalization of operators in the clause}

As was already hypothesized by Hengeveld (1989: 142), clausal operators tend to develop diachronically from an inner to an outer layer. ${ }^{17}$ Thus we see that in the course of time certain aspect markers $\left(\pi_{0}\right)$ may change into tense markers $\left(\pi_{3}\right)$. In their turn certain tense markers $\left(\pi_{3}\right)$ may eventually change into mood markers $\left(\Pi_{5}\right)$.

- from aspect to tense

According to the World Lexicon of Grammaticalization (Heine and Kuteva 2002: 231) there is a "general process whereby verbal aspect markers may be further grammaticalized to tense markers (see also Comrie 1976: 99-101; Bybee 1985: 196; Bybee and Dahl 1989: 56-57) ...”. This reference work lists various studies that describe the change from Continuous or Progressive (a special type of imperfective) to Present or simply to a more general Imperfective, for which Bybee et al. (1994: 141) offer the following rationale:

Since both present and imperfective meaning include the possibility of describing a situation as progressive, it is plausible to suppose that the more specific

17. Hengeveld (1989: 142): "Hypothesis 2: Diachronic developments in the field of operators tend to follow the direction $\pi_{1}>\pi_{2}>\pi_{3}>\pi_{4}$ " 
progressive grams may undergo development into either a present (in cases where the progressive was restricted to the present) or an imperfective (in cases where no temporal restrictions were in effect).

We also find that in many languages forms or constructions that were first used to express the PERFECT are later (also) used to indicate past tense. This is currently happening in e.g. Dutch and German, where the perfect construction ('have' + past participle) is now increasingly used to talk about events in the past:

Dutch

Hij heeft tien jaar geleden alles verkocht
he has ten year ago everything sold
'He sold everything ten years ago.'

In other languages (e.g. French), the perfect construction is now used to express a perfective meaning (Bybee et al. 1994; Heine and Kuteva 2003: 232). As was already mentioned above (section 3.2.3), the fact that the perfect may develop into a past tense or a perfective aspect has probably to do with the somewhat hybrid character of the perfect (cf. Bybee et al. 1994: 86). It is tense-like in that it involves a reference point, which is typical for deictic categories: the present perfect is used for a past event that has 'current relevance'. It is aspect-like in that it refers to an internal property of the event: its end point. Since it combines features of temporal and aspectual operators it may further grammaticalize either as a true tense or as a true aspect.

- from tense to mood

The change from Tense to Mood is clearly exemplified by future tense markers (Bybee et al. 1994: 205ff., 347-8), which often develop into markers of epistemic modality (possibility, probability). Below is an example from Swahili (Heine and Kuteva 2002: 143)

Swahili

(46) A-tu-ku-ja

C1-FUT-INF-come

'He will come.'

(47) A-tu-ku-wa nyumba-ni sasa

C1-FUT-INF-be house-LOC now

'He will be at home by now.'

\subsubsection{Grammaticalization of operators in the NP}

In the NP, too, there is a tendency for operators to widen their scope in the course of time, 'moving' from a lower/inner to a higher/outer layer in Figure 1. Thus we see that collective markers $\left(\omega_{0}\right)$ may become plural markers $\left(\omega_{2}\right)$, and that adnominal demonstratives $\left(\omega_{3}\right)$ may eventually change into definiteness or specificity markers $\left(\Omega_{4}\right)$. 


\section{- from collective to plural}

It is well known that plural markers often originate as collective markers (Frajzyngier 1997: 237). In other words, what we see here is that over time a classifying operator $\left(\omega_{0}\right)$ may turn into a quantifying operator $\left(\omega_{2}\right)$. The diachronic relation between Collective and Plural has been observed in many languages and language families across the globe, such as Ket (a language isolate), the Kartvelian languages, the Mesoamerican languages, and the Semitic languages (Rijkhoff 2002: 117).

The grammaticalization process can currently be observed in many languages, including Mandarin Chinese and Hmong. The suffix -men is often regarded as a plural marker in Mandarin Chinese. It behaves, however, differently when compared to plural markers in the western European languages: it is only used occasionally and its occurrence is still restricted to human nouns when reference is made to groups of people taken collectively: háizi-men '(a certain) group of children' (Norman 1988: 159). In Hmong Njua the collective classifier cov replaces all other classifiers to express plurality. Ratliff $(1991: 696,699)$ writes that cov still has a collective meaning (it probably derives from a word meaning 'bunches or clusters of fruit') and is on its way to become a real plural marker (see also Bisang 1996).

Hmong Njua (Harriehausen 1990: 115, 117)

(48) kuv yuav cov tsev

1SG buy PL house

'I buy (the) houses.'

\section{- from demonstrative to definite article}

The development from adnominal demonstrative to definite article (and beyond) is also well documented is many languages. The most elaborate study on this subject is probably still Greenberg 1978a (but see also Diessel 1999 and references therein on the grammaticalization of demonstratives in general). According to Greenberg's theory, four stages can be recognized in the process. Initially there is an adnominal demonstrative pronoun (Stage 0 ), which may or may not be marked for gender or class. In the following stage (Stage I), the demonstrative has lost its deictic function and has in fact turned into a definite article. The grammaticalization process need not stop here, for in Stage II the article indicates specificness, rather than definiteness. Ultimately, in Stage III, the element may become a gender/class marker, but only if the erstwhile attributive demonstrative pronoun was marked for gender or class. Otherwise the erstwhile demonstrative/article ends up as a noun marker, "a mere sign of nominality on the large majority of common nouns" (Greenberg 1978a: 69; see also Rijkhoff 2002: 92-96). ${ }^{18}$ The transition from demonstrative to definite article is clearly observed in Berbice Dutch Creole, where $d i$ is used both as a definiteness marker and a proximate demonstrative. The former precedes and the latter follows the noun:

18. On the special semantics of elements in the final stages of grammaticalization, see Greenberg (1991). 
Berbice Dutch Creole (Kouwenberg 1991: 111)

\author{
di wari di \\ the house this \\ 'this house'
}

\title{
4. Conclusion
}

In this paper, I have presented evidence in support of an updated version of the layered NP/clause model presented in Rijkhoff (2002). The synchronic evidence (section 3.1) included typological data from syntax, morphology and parts-of-speech systems (instances of isomorphism among lexical and grammatical modifiers that are represented at the same kind of layer in the NP and in the clause). The diachronic evidence for parallels between the layered structure of the clause and the NP consisted of two parts (section 3.2).

The first part dealt with historical relations between modifiers that appear in the same layer in the clause and the NP (section 3.2.2). It was shown that there is a diachronic connection between [a] elements marking the notions Collective (space) and Perfective (time), [b] expressions for spatial and temporal deixis, and [c] number markers for things and events. In the case of [a] and [b] there appears to be a clear preference for the metaphorical transition from space to time (cf. the hierarchy of conceptual domains in (38)), which does not necessarily mean, however, that modifiers in the NP become clause-level modifiers. For example, Gildea has argued that tense markers in Panare have developed from free rather than adnominal demonstrative pronouns. As a matter of fact, certain modifiers in the NP are also thought to have developed from independent forms or constructions (see e.g. Greenberg (1975) on numeral classifiers; Lehmann (1982) and Moravcsik (1997) on demonstratives). With respect to number markers in the clause and in the NP there is no consensus on the direction of change (from space to time or vice versa), which may have something to do with the non-linguistic nature of certain arithmetic notions or procedures (see note 16).

The diachronic connection between NP and clause internal modifiers (section 3.2.3) also points to a strong preference for unidirectional change, both in the NP and in the clause: from an inner to an outer layer. Since outer layer modifiers have inner layer modifiers in their scope, this implies that these cases of grammaticalization are all instances of scope increase. This goes against the popular idea that there is a correlation between grammaticalization and structural scope decrease (Song 2005: 795). It was argued that counterexamples to the change from inner to outer layer are due to the special semantics of the source item. For example, since the perfect combines features of the categories Tense (deixis) and Aspect (end point), it may develop in either direction, i.e. as an aspect ('inward') or as a tense ('outward'). 


\section{References}

Abney, S. P. 1987. The English Noun Phrase in its Sentential Aspect. PhD dissertation, MIT.

Anderson, S. R. \& Keenan, E. L. 1985. Deixis. In T. Shopen (ed.), Language Typology and Syntactic Description. Vol III: Grammatical categories and the lexicon, 259-308. Cambridge: CUP.

Bisang, W. 1996. Areal typology and grammaticalization: Processes of grammaticalization based on nouns and verbs in East and mainland South East Asian languages. Studies in Language 20(3): 519-597.

Blake, B. 1983. Structure and word order in Kalkatungu: The anatomy of a flat language. Australian Journal of Linguistics 3(2): 143-175.

Blake, B. 2001. The noun phrase in Australian languages. In J. Simpson et al. (eds.), Forty Years On: Ken Hale and Australian languages [No. 512], 415-426. Canberra: Pacific Linguistics.

Butler, C. S. 2003. Structure and Function: A guide to three major structural-functional theories. Part 1: Approaches to the simplex clause; Part 2: From clause to discourse and beyond. Amsterdam: John Benjamins.

Bybee, J. L. 1985. Morphology: A study of the relation between meaning and form [Typological Studies in Language 9]. Amsterdam: John Benjamins.

Bybee, J. L. \& Dahl, Ö. 1989. The creation of tense and aspect systems in the languages of the world. Studies in Language 13(1): 51-103.

Bybee, J., Perkins, R.D. \& Pagliuca, W. 1994. The Evolution of Grammar: Tense, aspect, and modality in the languages of the world. Chicago IL: The University of Chicago Press.

Clark, E. V. 1978. Locationals: Existential, locative, and possessive constructions. In J. H. Greenberg, C. A. Ferguson \& E. A. Moravcsik (eds.), Universals of Human Language. Vol. 4: Syntax, 85-126. Stanford CA: Stanford University Press,

Comrie, B. 1976. Aspect. Cambridge: CUP.

Comrie, B. 1985. Tense. Cambridge: CUP.

Craig, C. G. 1977. The Structure of Jacaltec. Austin TX: University of Texas Press.

Crevels, M. 1999. Concession: A typological study. PhD dissertation, University of Amsterdam.

Cuvalay, M. 1997. The Arabic Verb. A Functional Grammar approach to verbal expressions in Classical and Modern Arabic. Berlin/New York: Mouton de Gruyter.

Derbyshire, D. C. 1979. Hixkaryana [Lingua Descriptive Studies 1]. Amsterdam: North-Holland.

de Vries, L. 1989. Studies in Wambon and Kombai: Aspects of two Papuan languages of Irian Jaya. PhD dissertation, University of Amsterdam.

Denning, K. \& Kemmer, S. (eds). 1990. On Language: Selected writings of Joseph H. Greenberg. Stanford CA: Stanford University Press.

Diessel, H. 1999. Demonstratives: Form, function, and grammaticalization. Amsterdam: John Benjamins.

Dik, S. C. 1997. The Theory of Functional Grammar (second revised edn, Kees Hengeveld ed.). Part 1: The structure of the clause. Part 2: Complex and derived constructions. Berlin: Mouton de Gruyter.

Dik, S. C., Hengeveld, K., Vester, E. \& Vet, C. 1990. The hierarchical structure of the clause and the typology of adverbial satellites. In J. Nuyts, A. M. Bolkestein \& C. Vet (eds.), Layers and Levels of Representation in Language Theory: A functional view, 25-70. Amsterdam: John Benjamins.

Dryer, M. S. 1992. The Greenbergian word order correlations. Language 68(1): 81-138. 
$\mathrm{Du}$ Feu, V. M. 1987. The determinants of the noun in Rapanui. Journal of the Polynesian Society 96: 473-495.

Du Feu, V. M. 1989. Verbal parameters expressed in the NP in Rapanui. Paper presented at the Colloquium on NP Structure, University of Manchester, September 1989.

Du Feu, V. 1996. Rapanui [Routledge Descriptive Grammars]. London: Routledge.

Elliott, J. R. 2000. Realis and irrealis: Forms and concepts of the grammaticalisation of reality. Linguistic Typology 4(1): 55-90.

Everett, D. L. 2005. Cultural constraints on grammar and cognition in Pirahã. Current Anthropology 46: 621-646.

Farsi, A.A. 1968. Classification of adjectives. Language Learning 18: 45-60.

Frajzyngier, Z. 1977. The plural in Chadic. In: P. Newman and R. M. Newman (eds.), Papers in Chadic linguistics. Leiden: Afrika-Studiecentrum, 37-56.

Frajzyngier, Z. 1997. Grammaticalization of number: From demonstratives to nominal and verbal plural. Linguistic Typology 1(2): 193-242.

von Garnier, K. 1909. COM- als perfektierendes Praefix bei Plautus, SAM- im Rigveda, CYNbei Homer. Indogermanische Forschungen 25: 86-109.

Gerds, D. B. 1998. Incorporation. In A. Spencer \& A. M. Zwicky (eds.), The Handbook of Morphology, 84-100. Oxford: Blackwell.

Giegerich, H. J. 2005. Associative adjectives in English and the lexicon-syntax interface. Journal of Linguistics 41(3): 571-591.

Gil, D. 1993. Nominal and verbal quantification. Sprachtypologie und Universalienforschung (STUF) 46(4): 275-317.

Gildea, S. 1993. The development of tense markers from demonstrative pronouns in Panare (Cariban). Studies in Language 17(1): 53-73.

Greenberg, J. H. 1975. Dynamic aspects of word order in the numeral classifier. In C.N. Li (ed.), Word Order and Word Order Change, 29-45. Austin TX: University of Texas Press. (Reprinted in Denning \& Kemmer (eds), 227-240).

Greenberg, J. H. 1978a. How does a language acquire gender markers? In J. H. Greenberg, C.A. Ferguson \& E.A. Moravcsik (eds.), Universals of Human Language. Vol. 3: Word structure, 48-82. Stanford CA: Stanford University Press. (Reprinted in Denning \& Kemmer (eds), 241-270).

Greenberg, J. H. 1978b. Generalizations about numeral systems. In J.H. Greenberg, C.A. Ferguson \& E.A. Moravcsik (eds.), Universals of Human Language. Vol 3: Word Structure, 250-295.([Reprinted in Denning and Kemmer (eds), 271-309).

Greenberg, J. H. 1991. The last stages of grammatical elements; contrastive and expansive desemanticization. In E. Closs Traugott \& B. Heine (eds.), Approaches to Grammaticalization, Vol. II [Typological Studies in Language 19:2], 301-314. Amsterdam: John Benjamins,

Halliday, M.A.K. 2004. An Introduction to Functional Grammar (3rd edn, revised by C.M.I.M. Matthiessen). London: Arnold.

Harriehausen, B. 1990. Hmong Njua: Syntaktische Analyse einer gesprochenen Sprache mithilfe datenverarbeitungstechnischer Mittel und sprachvergleichende Beschreibung des südostasiatischen Sprachraumes [Linguistische Arbeiten 245]. Tübingen: Niemeyer.

Harms, R.T. \& Karttunen, F. (eds.). 1976. Papers from the Transatlantic Finnish Conference. Austin TX: Texas Linguistic Forum.

Haspelmath, M. 1997. From Space to Time: Temporal adverbials in the world's languages. München: Lincom. 
Heine, B. 1980. Determination in some East African languages. In G. Brettschneider \& C. Lehmann (eds.), Wege zur Universalienforschung: Sprachwissenschaftliche Beiträge zum 60. Geburtstag von Hansjakob Seiler, 180-186.Tübingen: Narr.

Heine, B. 1997. Cognitive Foundations of Grammar. Oxford: OUP.

Heine, B. 2003. Grammaticalization. In B. D. Joseph \& R. D. Janda (eds.), The Handbook of Historical Linguistics, 575-601. Oxford: Blackwell.

Heine, B., Claudi, U. \& Hünnemeyer, F. 1991. Grammaticalization. Chicago IL: The University of Chicago Press.

Heine, B. \& Kuteva, T. 2002. World Lexicon of Grammaticalization. Cambridge: CUP.

Hengeveld, K. 1988. Layers and operators [Working Papers in Functional Grammar 27]. Amsterdam: Dept. of Linguistics, University of Amsterdam.

Hengeveld, K. 1989. Layers and operators in Functional Grammar. Journal of Linguistics 25(1): $127-157$.

Hengeveld, K. 1992. Non-verbal Predication: Theory, typology, diachrony. Berlin: Mouton de Gruyter.

Hengeveld, K., Rijkhoff, J. \& Siewierska, A. 2004. Parts-of-speech systems and word order. Journal of Linguistics 40(3), 527-570.

Hengeveld, K. \& Rijkhoff, J. 2005. Mundari as a flexible language. Linguistic Typology 9(3), 406-431.

Hengeveld, K. \& Mackenzie, J. L. 2006. Functional discourse grammar. In K. Brown (ed.), Encyclopedia of Language and Linguistics, 2nd edn, Vol. 4, 668-676. Oxford: Elsevier.

Hengeveld, K. \& Mackenzie, J. L. 2008. Functional Discourse Grammar. Oxford: OUP.

Hopper, P. J. \& Closs Traugott, E. 2003. Grammaticalization (2nd edn). Cambridge: CUP.

Jackendoff, R. S. 1977. X-bar syntax. Cambridge MA: The MIT Press.

Kirk, A. 1923. An Introduction to the Historical Study of New High German. Manchester: The University of Manchester Press.

Kouwenberg, S. 1991. Berbice Dutch Creole: Grammar, texts, and vocabulary. PhD dissertation, University of Amsterdam.

Kulikov, L. 1998. Collective/Perfective. LINGTYP - discussion list for the Association for Linguistic Typology, 31 March 1998.

Kutsch Lojenga, C. 1994. Ngiti: A Central-Sudanic language of Zaire. Köln: Köppe.

Lakoff, G. 1993. The contemporary theory of metaphor. In A. Ortony (ed.), Metaphor and Thought (2nd edn), 202-251. Cambridge: CUP.

Lee, K. 1975. Kuseian Reference Grammar. Honolulu HI: University Press of Hawaii.

Lehmann, C. 1982. Thoughts on grammaticalization. Arbeiten des Kölner Universalien-Projekts 48.

Levebvre, C. 1998. Multifunctionality and variation among grammars: The case of the determiner in Haitian and in Fongbe. Journal of Pidgin and Creole Languages 13(1): 93-150.

Levebvre, C. \& Brousseau, A.-M. 2002. A Grammar of Fongbe [Mouton Grammar Library 25]. Berlin: Mouton de Gruyter.

Levi, J.N. 1973. Where do all those other adjectives come from? Papers from the ninth regional meeting of the Chicago Linguistic Society, April 13-15. In C. Corum, T. C. Smith-Stark \& A. Weiser (eds), You Take the High Node and I'll Take the Low Node. Papers from the 9th regional meeting of the Chicago Linguistic Society, April 13-15, 1973, 332-345. Chicago IL: Chicago Linguistic Society

Li, C.N. \& Thompson, S. A. 1981 [1989]. Mandarin Chinese - A functional reference grammar. Berkeley CA: University of California Press.

Matthews, G. H. 1965. Hidatsa Syntax. The Hague: Mouton. 
Miner, K. L. 1986. Noun stripping and loose incorporation in Zuni. International Journal of American Linguistics 52(3): 242-254.

Miner, K. L. 1989. A note on noun stripping. International Journal of American Linguistics 55: $476-7$.

Mithun, M. 1988. Lexical categories and the evolution of number marking. In M. Hammond \& M. Noonan (eds.), Theoretical Morphology: Approaches in modern linguistics, 211-234. New York NY: Academic Press.

Moravcsik, E. 1994. Inflectional morphology in the Hungarian noun phrase - a typological assessment. EuroTyp Working Papers VII(22), 1-58 (pages are numbered separately in each article).

Moravcsik, E. 1997. Parts and wholes in the Hungarian noun phrase - a typological study. In B. Palek (ed.), Typology: Prototypes, item orderings and universals. Proceedings of LP '96, 307-324. Prague: Charles University Press.

Mosel, U. \& Hovdhaugen, E. 1992. Samoan Reference Grammar. Oslo: Universitetsforlaget.

Newman, P. 1990. Nominal and Verbal Plurality in Chadic. Dordrecht: Foris.

Nordlinger, R. \& Sadler, L. 2004. Nominal tense in a crosslinguistic perspective. Language 80(4): 776-806.

Norman, J. 1988. Chinese. C: CUP.

Nuyts, J., Bolkestein, A.M. \& Vet. C. (eds.). 1990. Layers and Levels of Representation in Language Theory: A functional view. Amsterdam: John Benjamins.

Pica, P., Lemer, C., Izard, V. \& Dehaene, S. 2004. Exact and approximate arithmetic in an Amazonian indigene group. Science 306: 499-503.

Quirk, R. et al. 1985. A Comprehensive Grammar of the English Language. London: Longman.

Ratliff, M. 1991. Cov, the underspecified noun, and syntactic flexibility in Hmong. Journal of the American Oriental Society 111(4): 694-703.

Reh, M. 1985. Die Krongo-Sprache (Niinò Mó-di) - Beschreibung, Texte, Wörterverzeichniss. Berlin: Reimer.

Rijkhoff, J. 1988. A typology of operators: Toward a unified analysis of terms and predications [Working Papers in Functional Grammar 29]. Amsterdam: Dept. of Linguistics, University of Amsterdam.

Rijkhoff, J. 1990. Toward a unified analysis of terms and predications. In J. Nuyts, A. M. Bolkestein \& C. Vet (eds.), Layers and Levels of Representation in Language Theory: A functional view, 165-191. Amsterdam: John Benjamins.

Rijkhoff, J. 1992. The Noun Phrase: A typological study of its form and structure. PhD dissertation, University of Amsterdam.

Rijkhoff, J. 2002. The Noun Phrase. Oxford: OUP. (a revised and expanded paperback edition was published in 2004).

Rijkhoff, J. 2003. When can a language have nouns and verbs? Acta Linguistica Hafniensia 35: 7-38.

Rijkhoff, J. 2004. Iconic and non-iconic word order patterns: On symmetry in the NP and counter examples to Universal 20'. In H. Aertsen, M. Hannay \& R. Lyall (eds.), Words in Their Places: A Festschrift for J. Lachlan Mackenzie, 169-180. Amsterdam: Free University, Faculty of Arts.

Rijkhoff, J. 2007. Word classes. Language and Linguistics Compass 1(6): 709-726 [doi: 10.1111/j.1749-818X.2007.00030.x].

Rijkhoff, J. 2008a. Layers, levels and contexts in functional discourse grammar. In D. García Velasco \& J. Rijkhoff (eds.), The Noun Phrase in Functional Discourse Grammar [Trends in Linguistics. Studies and Monographs 195], 63-115. Berlin: Mouton de Gruyter. 
Rijkhoff, J. 2008b. Layering and iconicity in the noun phrase: Descriptive and interpersonal modifiers. Linguistics 46(4).

Rijkhoff, J. Forthcoming. On the co-variation between form and function of adnominal possessive modifiers in Dutch and English. In W. B. McGregor (ed.), The Expression of Possession [The Expression of Cognitive Categories 2]. Berlin: Mouton de Gruyter.

Rijkhoff, J. \& Seibt, J. 2005. Mood, definiteness and specificity: A linguistic and a philosophical account of their similarities and differences. Tidsskrift for Sprogforskning 3(2): 85-132.

Roberts, J. R. 1990. Modality in Amele and other Papuan languages. Journal of Linguistics 26: 363-401.

Schachter, P. 1985. Parts-of-speech systems. In T. Shopen (ed.), Language Typology and Syntactic Description. Vol I: Clause structure, 3-61. Cambridge: CUP.

Song, J. J. 2005. Grammaticalization and structural scope increase: Possessive-classifier-based benefactive marking in Oceanic languages. Linguistics 43(4): 795-838.

Stroomer, H. 1987. A Comparative Study of Three Southern Oromo Dialects in Kenya: Phonology, morphology and vocabulary [Cushitic Language Studies 6]. Hamburg: Buske.

van Baarda, M.J. 1908. Leiddraad bij het Bestuderen van 't Galela'sch Dialekt, op het Eiland Halmaheira (Manual for the study of the Galela dialect, on the island of Halmahera). The Hague: Nijhoff.

Van Valin, R. D., Jr. \& LaPolla, R. J. 1997. Syntax: Structure, meaning and function. Cambridge: CUP.

Vet, C. 1986. A pragmatic approach to tense in functional grammar [Working Papers in Functional Grammar 16]. Amsterdam: Dept. of Linguistics, University of Amsterdam. 